\title{
Information provision in neurological dysphagia - impact of a booklet on patient's knowledge, happiness and satisfaction.
}

\author{
Juliana Ferreira ${ }^{1}$ and Margarida Figueiredo-Braga ${ }^{1}$ \\ ${ }^{1}$ University of Porto
}

May 5, 2020

\begin{abstract}
Dysphagia has physiological and psychosocial consequences for patients and their caregivers. Although the psychological impact of dysphagia can be devastating, research has privileged the physiological and clinical outcomes of the disorder. Provision of information may enhance patient's knowledge and ability to cope with the disorder. In the present study, an original booklet and routine information procedures where compared regarding satisfaction with communication, subjective feeling of happiness, and knowledge about dysphagia in patients and caregivers. A convenience sample of 27 patients with neurological dysphagia was allocated to an experimental group $(\mathrm{n}=14)$ who received the booklet, and a control group $(\mathrm{n}=13)$ submitted to the routine information procedures. Evaluation of type and severity of dysphagia was performed in both groups, and participants were surveyed at two moments (T1 and T2) regarding subjective well-being - Subjective Happiness Scale (SHS) and satisfaction with the communication- Satisfaction Survey adapted from Patients Satisfaction with the Interview Assessment Questionnaire (PSIAC). Patient's knowledge about dysphagia was evaluated at At T2. Statistically significant higher level of SHS and knowledge about dysphagia was found in the experimental group at T2. Conversely, Satisfaction was lower in the control group at T2 compared with T1. This study provides compelling arguments for combining verbal and written information in patients with neurological dysphagia. The use of the booklet made a significant contribution to patients' knowledge.
\end{abstract}

\section{Keywords}

healthcare satisfaction; health literacy; neurological dysphagia; deglutition; deglutition disorders

\section{Introduction}

Dysphagia is a serious disorder with the potential of psychologically and socially affect patients ${ }^{1}$. Consequences may include malnutrition, dehydration and respiratory complications which affect the patient's quality of life and are responsible for increasing number of hospital admissions. Psychosocially the effect of dysphagia can be devastating, compromising patient's wellbeing and impairing social and family relationship ${ }^{1-3}$.

The food modifications imposed by dysphagia can make the meal time uncomfortable, difficult and even cause physical and emotional suffering ${ }^{4}$. For humans, food goes far beyond caloric and water requirements for their survival. Eating is also considered a social and pleasurable act, and food is seen as a source of pleasure, mediated by different flavours, consistencies and appearances ${ }^{1-5}$. Adaptations imposed by the presence of dysphagia lead to food selection and restriction, modifying social activities and daily routines ${ }^{1,2}$.

For the effective management of oropharyngeal dysphagia, it is important to consider the patient's functional health status and to assess the impact of dysphagia on functional and psychosocial aspects ${ }^{1}$. A diagnosis of dysphagia alone or with other functional comorbidities is related to a poorer prognosis and more demanding rehabilitation. This is due to the risk of malnutrition during post-hospitalization and of respiratory complications that may compromise the rehabilitation ${ }^{1,6}$. Dehydration is another possible consequence that 
interferes with the recovery of the patient - although diet modification does not present pulmonary risks and thickeners respect water bioavailability, the water supply may be insufficient. The use of thickener impairs the water supply due to a voluntary reduction of fluid intake related with a lower drive to consume liquids ${ }^{7-9}$.

There is a paucity of studies regarding the psychosocial impact of dysphagia. This chronic condition erodes patient's quality of life, psychosocial well-being and satisfaction ${ }^{10,11}$.

Comprehensible information for patients and caregivers is known to reduced psychological impact of the diseases and enhance satisfaction with health care ${ }^{9}$.Studies carried out in several clinical areas indicate however that patients desire more information about symptoms, biopsychosocial consequences, pain management and therapy management ${ }^{14-17}$. The information received at the time of hospital discharge for example is generally described as insufficient and/or unspecific, in opposition to patient's preferences for individualized, complete and simple information. Knowledge acquired through information delivery allows patients to better cope with therapy, having a positive impact on anxiety management. More informed patients and caregivers are more autonomous and self-confidents in their ability to deal with symptoms, and more prepared for shared decision-making $9,14,15$.

The information delivered to the patient during hospitalization allows him to create a realistic perspective and expectations of his illness, facilitating the assessment and management of necessary changes. Planning the information to be given before discharge is important to prevent most of the doubts after discharge ${ }^{9,14,15}$. After the diagnosis, it is necessary to instruct patients with dysphagia on swallowing strategies, how to prepare solid and liquid food, establish the rehabilitation plan and advise about signs of complications ${ }^{1,5,16}$. Clear and defined terminology capable of guiding the production of different food consistencies is necessary to ensure the patient's clinical condition and the evolution of the swallowing therapy. It is essential that all the professionals in the team are conscious of the safest diet for each patient and that they use the same standardized language ${ }^{1,16}$. The provision of written information can avoid confusion in the language used and consequently in the diet adopted, and reinforce the indications given by the speech and language therapist after clinical and instrumental evaluation ${ }^{1,16,17}$.

The purpose of this exploratory study was to evaluate the impact of an original booklet in the subjective wellbeing, satisfaction with communication and knowledge about dysphagia and to compare it with the routine delivery of information about the disease and treatment.

\section{Materials and Methods}

Patients diagnosed with neurological dysphagia for less than two weeks and hospitalized in an acute hospital setting were invited to participate in this study. Inclusion criteria was also a severity degree of the dysphagia equal to or greater than three determined according to the Functional Oral Intake Scale (FOIS) ${ }^{18}$. Patients unable to read or understand the manual due to language alterations, cognitive deficits and/or illiteracy, were excluded. Cognitive state was considered according the clinical process.

Patients fulfilling the inclusion criteria who agreed to participate in the study were randomly allocated to the experimental and the control group using an online software ${ }^{19}$. Assessment was performed at T1 by the speech and language therapist, after establish the first contact with the patient and evaluation of the degree of dysphagia. Patents fulfilled a sociodemographic questionnaire, the Portuguese version of the Subjective Happiness Scale (SHS $)^{20}$ and the adapted version of the Patients Satisfaction with the Interview Assessment Questionnaire (PSIAQ $)^{21}$. The booklet was presented to the patients included in the experimental group, during a speech therapy session. In the control group, patients were submitted to the routine procedures. A week later (T2) both groups of patients fulfil the same battery of instruments, and a questionnaire evaluating the information received and recalled (figure 1).

\section{Instruments}

To assess the patient satisfaction with health care, an adapted version of the Patient Satisfaction with the Interview assessment Questionnaire (PSIAQ) developed by Delvaux and his colleagues was used. This instrument is designed to measure three important dimensions of clinical communication (presentation, 
information and support) and presents good psychometric qualities: for satisfaction with facilitating and listening factors a Cronbach's $\alpha$ coefficient of 0.84 and for the satisfaction with informing and reassuring factors a value of 0.72 . Questions are presented using a four-point Likert, and the maximum satisfaction score is 4 .

The Portuguese version of the Subjective Happiness Scale (SHS) permitted to evaluate patient's subjective wellbeing ${ }^{22}$. The scale is a 4 -item scale with high internal consistency and good to excellent reliability ${ }^{22}$. Responses were made on a 7-point scale, measuring to what extent does the characterization describe them.

An original questionnaire assessed knowledge about dysphagia and the patient's knowledge about the adaptations in the consistency of food.

Authorization was requested and obtained from the ethics committee of two hospitals with acute hospitalization. All the patients received oral and written information about the study protocol and signed an informed consent form.

Data analysis was performed using descriptive and inferential statistics, using SPSS-24.0 software (Statistical Package for the Social Sciences). For the comparison of the two groups, the Mann-Withney test was applied and for comparison of the moment before and the moment after the intervention, the Wilcoxon test was applied for a population median. The binomial test was used in the association of the information questions patients have about dysphagia as a function of the group.

\section{Results}

The sample included 27 participants divided into a control group $(\mathrm{n}=13)$ and an experimental group $(\mathrm{n}=14)$ (Table 1). The evaluation of the severity of the dysphasia revealed a mean FOIS score of 4.2 for the control group and 4.6 for the experimental group, corresponding to similar oral diet and a mild to severe dysphagia.

Patients included in the control and in the experimental group showed similar sociodemographic and clinical characteristics (data not shown).

\section{Satisfaction with the communication (PSIAC)}

The evaluation of the patient satisfaction with the communication, revealed similar level of satisfaction in both groups at T1 and T2. All the questions presented similar scores with exception the question "ability of the health professionals to reassure me", statistically higher in the experimental group at both assessments.

Comparison of the patient satisfaction in each group, between $\mathrm{T} 1$ and $\mathrm{T} 2$ revealed a statistically significant $(\mathrm{p}=0.026)$ lower satisfaction level at $\mathrm{T} 2$ in the control group.

\section{Subjective Happiness (SHS)}

Participants of the control group presented statically higher scores in the SHS at T1 and T2 in the third $(\mathrm{p}=0,008)$ and forth $(\mathrm{p}=0,002)$ items of the scale, when compared with the experimental group (Table 2$)$.

Comparison of the SHS scores between T1 and T2 revealed a significantly lower score in the control group at $\mathrm{T} 2$ in the first item of the scale $(\mathrm{p}=0.014)$. On the contrary, in the experimental group statistically significant higher scores were detected in items "In general, I consider myself. .." and "Compared to most of my peers, I consider myself..." at T2 $(\mathrm{p}=0,046$ and $\mathrm{p}=0,014$ respectively) when compared with $\mathrm{T} 1$ (Table 3$)$.

\section{Knowledge about dysphagia}

Evaluation of information about dysphagia revealed statistically significant differences between the two groups. The experimental group reported higher prevalence of agreement in the items "I know I must be careful when I cook my meals and the way I sit at the table" and "If necessary, I can explain how my meals should be prepared" ( $\mathrm{p}=0,033$ and $\mathrm{p}=0,016$ respectively) when compared with the control group. In the item "I know how to prepare my drinks without putting myself in danger" a border line higher score was also found in the experimental group $(\mathrm{p}=0,57)$ (Table 4$)$. 


\section{Discussion}

The results showed a positive impact of the booklet utilization in the patient's knowledge about their disease. In previous studies, patients more informed about their diseases showed higher ability to comply with clinical manifestations and more efficient in avoiding difficulties ${ }^{23,24}$. Patients using the booklet report to have more information on preparing meals and seat at the table safely. Moreover, they are supplied with information they can consult as many times as needed, and we may anticipate that they will be more prepared to prevent and deal with clinical complications after discharge,

These patients could additionally be readier to follow the recommendations given by the professionals to ensure efficacy and safety in swallowing ${ }^{24}$. They declare to rely on the professional's ability to reassure them when needed.

Studies have shown that patients with more knowledge adhere more frequently to therapy and patient adherence to treatment recommendations is an important issue for healthcare providers. Neurological dysphagia requires complex and specific interventions, with altered daily patterns of behaviour ${ }^{3,4,24}$, which may be difficult to follow and undermine patient's compliance. Patients and their caregivers have reported feelings of concern, fear, and anxiety in dealing with dysphagia ${ }^{25}$. These feelings can be explained by demanding tasks related with diet management, including changes in food consistency, body positioning and the use of specialized equipment. Lack of information and follow-up may provoke feelings of incompetence and over-responsibility to both patients and those who support them at home ${ }^{25}$.

The role of communication between patients and health professionals in clinical outcomes and satisfaction with care has been confirmed in the literature ${ }^{26,27}$. Patients submitted to the routine procedures presented decreased satisfaction at the second evaluation. This may be related with the difficulties in delivering information, without written support, when professionals are professionally overloaded or unprepared. On the other hand, patient's anxiety may interfere with their ability to recall and understand information adequately delivered ${ }^{27}$.

This study has several limitations. A limitation is the small number of patients included, although they presented similar type and severity of dysphagia. Also, the short follow up period thus not permit to infer the impact of the intervention after discharge. A re-evaluation in ongoing, associated with the monitoring of hospital admissions and complications of the patients surveyed.

The use of written information in hospitalized patients has shown to be a resource that allows to improve the subjective sensation of happiness in patients with neurological dysphagia, a debilitating and distressing disorder.

\section{Summary}

The results from this study provide an argument for combining verbal and written information about dysphagia. The delivery of a booklet was associated with higher subjective happiness and higher satisfaction with communication with health professionals one week later. The use of informative written support made a significant contribution to patients' knowledge. Patients reported to be more informed about how to prepare their meals, what signs they should be aware of, and that their swallowing problem compromises their overall health.

Acknowledgements: The authors would like to acknowledge the Hospital's Administration for allowing data collection.

Authors' contributions: Both authors were responsible for the design of the study. The first author provided data entry and data editing, the statistical analyses and the draft of the manuscript. The second author discussed the methods and results, assisted in determining the objectives and reviewed the manuscript. Both authors have read and approved the final version of the manuscript.

Declaration of conflict of interest: The authors have no conflict of interest to declare. 
Ethical approval: Ethical approval was granted by the Evaluation Committee for Academic Works and the Ethical Committee of the Hospitals. Document number 71/2018 and 018/18.

Funding: The authors received no specific funding for this work.

Disclosures: None

\section{References}

[1] Clavé P, Peris P. Guía de Diagnóstico y de Tratamiento Nutricional y Rehabilitador de la Disfagia Orofaríngea. 3 ed. Barcelona: Editorial Glosa; 2015.

[2] Drozdz D, Mancopes R, Silva A, Reppold C. Analysis of the level of dysphagia, anxiety, and nutricional status before and after speech therapy in patients with stroke. Int Arch Otorhinolaryngol. 2014; pp. 172-177.

[3] Ashwini M, MacDonald N, Shune S. The Burden of Dysphagia on Family Caregiversof the Elderly: A Systematic Review. Geriatrics . 2018; 3, 30;

[4] Bretan O, Henry M, Kerr-Corrêa F. Dysphagia and emotional distress. Arq Gastroenterol. 1996 AprJun;33(2):60-5.

[5] Ayres A, Jotz G, Rieder C, Schuh A, Olchik M. The Impact of Dysphagia Therapy on Quality of Life in Patients with Parkinson's Disease as Measured by the Swallowing Quality of Life Questionnaire (SWALQOL). Int Arch Otorhinolaryngol . 2016; 20(3): 202-206.

[6] Iwamoto M, Higashibeppu N, Arioka Y, Nakaya, Y. Swallowing rehabilitation with nutrition therapy improves clinical outcome in patients with dysphagia at an acute care hospital. The Journal of Medical Investigation . 2014

[7] Clavé P, de Kraa M, Arreola V, Girvent M, Farré R, Palomera E. The effect of bolus viscosity on swallowing function in neurogenic dysphagia. Aliment PharmacolTher . 2006;24:1385-94.

[8] Clavé P, Arreola V, Romea M, Medina L, Palomera E, Serra-Prat M. Accuracy of the volume-viscosity swallow test for clinical screening of oropharyngeal dysphagia and aspiration. Clin Nutr .2008;27(6):806-15.

[9] Cichero J. Thickening agents used for dysphagia management: effect on bioavailability of water, medication and feelings of satiety.Nutrition journal. 2013; 12, 54 .

[10] Ekberg O, Hamdy S, Woisard V, Wuttge-Hannig A, Ortega P. Social and psychological burden of dysphagia: its impact on diagnosis and treatment. Dysphagia . 2002 Spring;17(2):139-46.

[11] Learned S. Understanding dysphagia: the social and emotional Impact. Rehabilitation, Human Resources and Communication Disorders Undergraduate Honors Theses. 2014; 25.

[12] Scottish Intercollegiate Guidelines Network (SIGN). Management of patients with stroke. Rehabilitation, prevention and management of complications, and discharge planning. A national clinical guideline. Edinburgh: Scottish Intercollegiate Guidelines Network (SIGN); 2002 Nov. (SIGN publication; no. 64).http://www.sign.ac.uk.

[13] Fagermoen, M, Hamilton G. Patient information at discharge - A study of a combined approach. Patient Education and Counseling . 2005;63:169-176.

[14] Cebeci F, Celik S. Discharge training and counselling increase self-care ability and reduce postdischarge problems in CABG patients.J Clin Nurs. 2008;17(3):412-20.

[15] Buurman B, Verhaegh K, Smeulers M, Vermeulen H, Geerlings S, Smorenburg S, Rooij S. Improving handoff communication from hospital to home: the development, implementation and evaluation of a personalized patient discharge letter. International Journal for quality in health care. 2016. 1-7.

[16] Sandler D, Mitchell J, Fellows A, Garner S. Is an information booklet for patients leaving hospital helpful and useful?.BMJ . 1989; 298:870-874. 
[17] Amaral A, Rodrigues L, Furlan R, Vicente L, Motta A. Fonoaudiologia e nutrição em ambiente hospitalar: análise de terminologia de classificação das consistências alimentares. CoDas ; 2015:541-9.

[18] Crary M, Carnaby M, Groher M. Initial psychometric assessment of a functional oral intake scale for dysphagia in stroke patients.Archives of Physical Medicine and Rehabilitation. 2005 ;86 (8), pp. 1516-1520.

[19] Random.org. Dublin: 2010. Available from: https://www.random.org/company/

[20] Spagnoli P, Caetano A, Silva A. Psychometric Properties of a Portuguese Version of the Subjective Happiness Scale. Soc Indic Res ; 2010.

[21] Delvaux N, Razavi D, Marchal S, Bredart A, Farvacques C, Slachmuylder J. Effects of a 105 hours psychological training program on attitudes, communication skills and occupational stress in oncology: a randomised study. British journal of cancer . 2004; 90: 106-14.

[22] Lyubomirsky, S., \& Lepper, H. S. (1999). A measure of subjective happiness: Preliminary reliability and construct validation. Social Indicators Research, 46, 137-155.

[23] Jones E, Speyer R, Kertscher B, Denman D, Swan K, Cordier R. Health-Related Quality of Life and Oropharyngeal Dysphagia: A Systematic Review. Dysphagia. 2017, 33(2):141-172.

[24] Krekeler B, Broadfoot C, Johnson S, Connor N, Rogus-Pulia N. Patient Adherence to Dysphagia Recommendations: A Systematic Review.Dysphagia. 2017, 33(2):173-184.

[25] Arslan S, Demir N, Karaduman A. The Anxiety Level of Caregivers of Neurological Patients with Dysphagia. Dysphagia. 2017, 32(4):570-574.

[26] OschM , Sep M, Vliet M, Dulmen S, Bensing M. Reducing patients' anxiety and uncertainty, and improving recall in bad news consultations. Health Psychology : 2014, 33(11), 1382-1390

[27] Stewart M, Brown J, Donner A, McWhinney I, Oates J, Weston W, Jordan J.The Impact of PatientCentered Care on Outcomes. Journal of Family Practice. 2000; 49(No. 9).1-9.

Tables

Table 1. Sociodemographic and clinical characterization of the sample

\begin{tabular}{lll}
\hline Participants $n=27$ & & $\%$ \\
\hline Gender & Male & $81,5 \%$ \\
& Female & $18,5 \%$ \\
Academic qualifications & Undergraduate degree & $70,4 \%$ \\
Household & Graduate degree & $14,8 \%$ \\
& Spouse & $51,8 \%$ \\
& Son or daughter & $18,5 \%$ \\
& Caregivers & $11,1 \%$ \\
Clinical Diagnosis & Alone & $3,7 \%$ \\
& Others & $14,8 \%$ \\
& Stroke & $81,5 \%$ \\
& Traumatic brain injury & $3,7 \%$ \\
& Other neurological disease & $14,8 \%$ \\
\hline
\end{tabular}

Table 2. Comparison of the SHS scores in each group at T1 and T2 


\begin{tabular}{|c|c|c|c|}
\hline & Control Group & Experimental Group & $p^{1}$ \\
\hline $\begin{array}{l}\text { The causes of my } \\
\text { eating problem are } \\
\text { clear to me } \\
\text { I don't agree }\end{array}$ & $\begin{array}{l}\text { The causes of my } \\
\text { eating problem are } \\
\text { clear to me } \\
0\end{array}$ & $\begin{array}{l}\text { The causes of my } \\
\text { eating problem are } \\
\text { clear to me } \\
2(14,3 \%)\end{array}$ & \\
\hline I agree & $13(100 \%)$ & $12(85,7 \%)$ & 1,000 \\
\hline $\begin{array}{l}\text { I know that Dysphagia } \\
\text { is a swallowing problem } \\
\text { caused by my disease }\end{array}$ & $\begin{array}{l}\text { I know that Dysphagia } \\
\text { is a swallowing problem } \\
\text { caused by my disease }\end{array}$ & $\begin{array}{l}\text { I know that Dysphagia } \\
\text { is a swallowing problem } \\
\text { caused by my disease }\end{array}$ & \\
\hline I don't agree & 0 & 0 & \\
\hline I agree & $13(100 \%)$ & $14(100 \%)$ & 1,000 \\
\hline $\begin{array}{l}\text { I know what I can eat } \\
\text { without putting myself } \\
\text { in danger }\end{array}$ & $\begin{array}{l}\text { I know what I can eat } \\
\text { without putting myself } \\
\text { in danger }\end{array}$ & $\begin{array}{l}\text { I know what I can eat } \\
\text { without putting myself } \\
\text { in danger }\end{array}$ & \\
\hline I don't agree & $5(38,5 \%)$ & $1(7,1 \%)$ & \\
\hline I agree & $8(61,5 \%)$ & $13(92,9 \%)$ & 0,383 \\
\hline $\begin{array}{l}\text { I know how to prepare } \\
\text { my drinks without }\end{array}$ & $\begin{array}{l}\text { I know how to prepare } \\
\text { my drinks without }\end{array}$ & $\begin{array}{l}\text { I know how to prepare } \\
\text { my drinks without }\end{array}$ & \\
\hline $\begin{array}{l}\text { putting myself in } \\
\text { danger }\end{array}$ & $\begin{array}{l}\text { putting myself in } \\
\text { danger }\end{array}$ & $\begin{array}{l}\text { putting myself in } \\
\text { danger }\end{array}$ & \\
\hline I don't agree & $10(76,9 \%)$ & $3(21,4 \%)$ & \\
\hline I agree & $3(23,1 \%)$ & $11(78,6 \%)$ & 0,057 \\
\hline I know that my & I know that my & I know that my & \\
\hline difficulty in swallowing & difficulty in swallowing & difficulty in swallowing & \\
\hline health & health & health & \\
\hline I don't agree & $3(23,1 \%)$ & 0 & \\
\hline I agree & $10(76,9 \%)$ & $14(100 \%)$ & 0,541 \\
\hline I know that my & I know that my & I know that my & \\
\hline difficulty in swallowing & difficulty in swallowing & difficulty in swallowing & \\
\hline $\begin{array}{l}\text { influences my overall } \\
\text { health }\end{array}$ & $\begin{array}{l}\text { influences my overall } \\
\text { health }\end{array}$ & $\begin{array}{l}\text { influences my overall } \\
\text { health }\end{array}$ & \\
\hline I don’t agree & $6(46,2 \%)$ & 0 & \\
\hline I agree & $7(53,8 \%)$ & $14(100 \%)$ & 0,189 \\
\hline $\begin{array}{l}\text { I know I must be } \\
\text { careful when I cook mv }\end{array}$ & $\begin{array}{l}\text { I know I must be } \\
\text { careful when I cook mv }\end{array}$ & $\begin{array}{l}\text { I know I must be } \\
\text { careful when I cook mv }\end{array}$ & \\
\hline $\begin{array}{l}\text { meals and how I sit at } \\
\text { the table }\end{array}$ & $\begin{array}{l}\text { meals and how I sit at } \\
\text { the table }\end{array}$ & $\begin{array}{l}\text { meals and how I sit at } \\
\text { the table }\end{array}$ & \\
\hline I don't agree & $7(53,8 \%)$ & $3(21,4 \%)$ & \\
\hline I agree & $6(46,2 \%)$ & $11(78,6 \%)$ & 0,033 \\
\hline $\begin{array}{l}\text { I know that there are } \\
\text { some signs of alert }\end{array}$ & $\begin{array}{l}\text { I know that there are } \\
\text { some signs of alert }\end{array}$ & $\begin{array}{l}\text { I know that there are } \\
\text { some signs of alert }\end{array}$ & \\
\hline when I am eating & when I am eating & when I am eating & \\
\hline I don't agree & $8(61,5 \%)$ & $2(14,3 \%)$ & \\
\hline I agree & $5(38,5 \%)$ & $12(85,7 \%)$ & 0,143 \\
\hline If necessary, I can & If necessary, I can & If necessary, I can & \\
\hline explain how my meals & explain how my meals & explain how my meals & \\
\hline $\begin{array}{l}\text { should be prepared } \\
\text { I don't agree }\end{array}$ & should be prepared & should be prepared & \\
\hline $\begin{array}{l}\text { I don't agree } \\
\text { I agree }\end{array}$ & $13(100 \%)$ & $7(50 \%)$ & \\
\hline I agree & 0 & $7(50 \%)$ & 0,016 \\
\hline
\end{tabular}




\begin{tabular}{llll}
\hline & Control Group & Experimental Group & $p^{1}$ \\
\hline I know I can do & I know I can do & I know I can do & \\
therapy to improve & therapy to improve & therapy to improve & \\
how and what I eat & how and what I eat & how and what I eat & \\
I don't agree & $1(7,7 \%)$ & 0 & \\
I agree & $12(92,3 \%)$ & $14(100 \%)$ & 0,845 \\
\hline
\end{tabular}

${ }^{1}$ Mean \pm Standart Deviation ${ }^{2}$ Mann-Whitney test

Table 3. Comparison of the SHS scores in each group between T1 and T2

\begin{tabular}{llll}
\hline Scaleof Subjective Happiness & $\mathrm{T} 1$ & $\mathrm{~T} 2$ & $p$ \\
\hline Control Group & Control Group & Control Group & Control Group \\
SHS total & $4,25 \pm 1,21^{1}$ & $4,13 \pm 1,20$ & $\mathbf{0 , 0 5 8 ^ { 2 }}$ \\
Q1 & $4,31 \pm 1,49$ & $3,85 \pm 1,46$ & $\mathbf{0 , 0 1 4}$ \\
Q2 & $4,46 \pm 1,45$ & $4,31 \pm 1,49$ & 0,157 \\
Q3 & $4,54 \pm 1,56$ & $4,54 \pm 1,39$ & 1,000 \\
Q4 & $3,69 \pm 1,70$ & $3,85 \pm 1,62$ & 0,317 \\
Experimental Group & & & \\
SHS total & $4,05 \pm 0,67^{1}$ & $4,20 \pm 0,64$ & $0,185^{2}$ \\
Q1 & $3,93 \pm 0,73$ & $4,21 \pm 0,70$ & 0,046 \\
Q2 & $3,86 \pm 0,77$ & $4,29 \pm 0,99$ & $\mathbf{0 , 0 1 4}$ \\
Q3 & $3,00 \pm 1,11$ & $3,00 \pm 1,11$ & 1,000 \\
Q4 & $5,43 \pm 0,76$ & $5,29 \pm 0,91$ & 0,414 \\
\hline
\end{tabular}

${ }^{1}$ Mean \pm Standart Deviation ${ }^{2}$ One sided-teste - Wilcoxon Test

Table 4. Comparison of the level of knowledge about dysphagia between the different groups

\begin{tabular}{llll}
\hline & Control Group & Experimental Group & $p^{1}$ \\
\hline The causes of my & The causes of my & The causes of my \\
eating problem are & eating problem are & $\begin{array}{l}\text { eating problem are } \\
\text { clear to me }\end{array}$ & \\
clear to me & 0 & $2(14,3 \%)$ & \\
I don't agree & $13(100 \%)$ & $12(85,7 \%)$ & 1,000 \\
I agree & I know that Dysphagia & I know that Dysphagia & \\
I know that Dysphagia & is a swallowing problem & is a swallowing problem & \\
is a swallowing problem & caused by my disease & caused by my disease & \\
caused by my disease & 0 & 0 & 1,000 \\
I don't agree & $13(100 \%)$ & $14(100 \%)$ & \\
I agree & I know what I can eat & I know what I can eat & \\
I know what I can eat & without putting myself & without putting myself & \\
without putting myself & in danger & in danger & \\
in danger & $5(38,5 \%)$ & $1(7,1 \%)$ & 0,383 \\
I don't agree & $8(61,5 \%)$ & $13(92,9 \%)$ \\
I agree & I know how to prepare & I know how to prepare & \\
I know how to prepare & my drinks without & my drinks without & \\
my drinks without & putting myself in & putting myself in & \\
putting myself in & danger & danger & \\
danger & &
\end{tabular}




\begin{tabular}{|c|c|c|c|}
\hline & Control Group & Experimental Group & $p^{1}$ \\
\hline I don't agree & $10(76,9 \%)$ & $3(21,4 \%)$ & \\
\hline I agree & $3(23,1 \%)$ & $11(78,6 \%)$ & 0,057 \\
\hline I know that my & I know that my & I know that my & \\
\hline difficulty in swallowing & difficulty in swallowing & difficulty in swallowing & \\
\hline can endanger my & can endanger my & can endanger my & \\
\hline health & health & health & \\
\hline I don't agree & $3(23,1 \%)$ & 0 & \\
\hline I agree & $10(76,9 \%)$ & $14(100 \%)$ & 0,541 \\
\hline I know that my & I know that my & I know that my & \\
\hline difficulty in swallowing & difficulty in swallowing & difficulty in swallowing & \\
\hline influences my overall & influences my overall & influences my overall & \\
\hline health & health & health & \\
\hline I don't agree & $6(46,2 \%)$ & 0 & \\
\hline I agree & $7(53,8 \%)$ & $14(100 \%)$ & 0,189 \\
\hline I know I must be & I know I must be & I know I must be & \\
\hline $\begin{array}{l}\text { careful when I cook my } \\
\text { meals and how I sit at }\end{array}$ & $\begin{array}{l}\text { careful when I cook my } \\
\text { meals and how I sit at }\end{array}$ & $\begin{array}{l}\text { careful when I cook my } \\
\text { meals and how I sit at }\end{array}$ & \\
\hline the table & the table & the table & \\
\hline I don't agree & $7(53,8 \%)$ & $3(21,4 \%)$ & \\
\hline I agree & $6(46,2 \%)$ & $11(78,6 \%)$ & 0,033 \\
\hline I know that there are & I know that there are & I know that there are & \\
\hline some signs of alert & some signs of alert & some signs of alert & \\
\hline when I am eating & when I am eating & when I am eating & \\
\hline I don't agree & $8(61,5 \%)$ & $2(14,3 \%)$ & \\
\hline I agree & $5(38,5 \%)$ & $12(85,7 \%)$ & 0,143 \\
\hline If necessary, I can & If necessary, I can & If necessary, I can & \\
\hline explain how my meals & explain how my meals & explain how my meals & \\
\hline should be prepared & should be prepared & should be prepared & \\
\hline I don't agree & $13(100 \%)$ & $7(50 \%)$ & \\
\hline I agree & 0 & $7(50 \%)$ & 0,016 \\
\hline I know I can do & I know I can do & I know I can do & \\
\hline therapy to improve & therapy to improve & therapy to improve & \\
\hline how and what I eat & how and what I eat & how and what I eat & \\
\hline I don't agree & $1(7,7 \%)$ & 0 & \\
\hline I agree & $12(92,3 \%)$ & $14(100 \%)$ & 0,845 \\
\hline
\end{tabular}

${ }^{1}$ Binomial test

Figure 1. Methods 


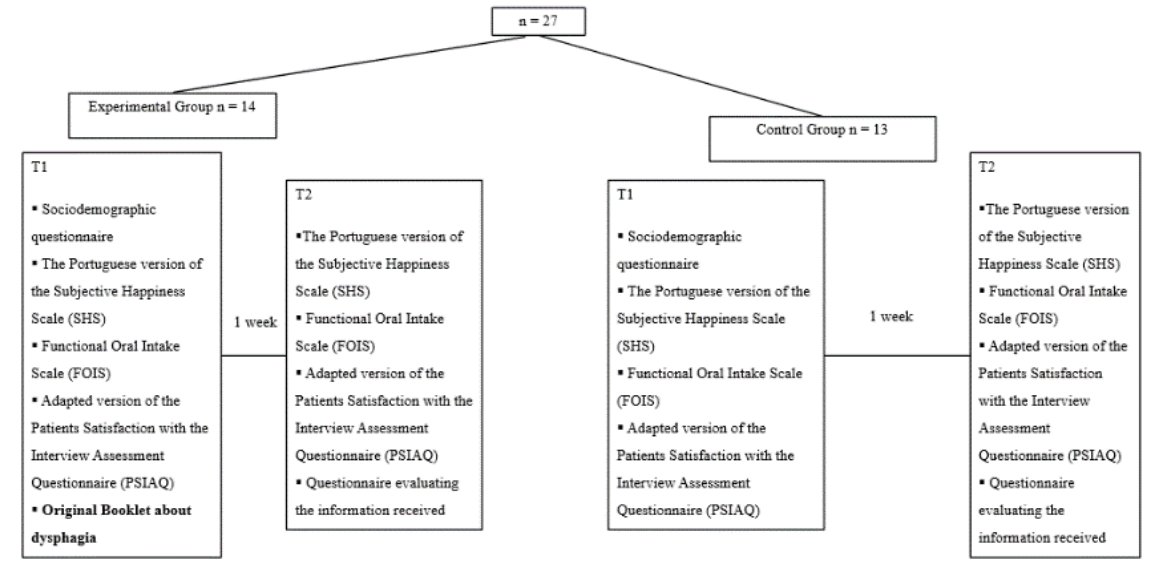

